\title{
LATERAL CLOSING WEDGE OSTEOTOMY FOR CUBITUS VARUS: A CASE REPORT
}

\author{
Prakriti Raj Kandel ${ }^{1}$, Rajiv Baral ${ }^{1}$, NivaChitrakar $^{2}$, Gyaneshwar Prasad Singh ${ }^{3}$, Laxmi Pathak ${ }^{4}$
}

\begin{abstract}
Supracondylar fracture is the most common fracture in children and yet are not treated timely or properly leading to various complications, cubitusvarus being the most common delayed complication ${ }^{1-5}$. There are various osteotomies that have been proposed for correcting cubitusvarus, but they all have their limitations. In this case study, we have reviewed the functional and cosmetic results of a simple lateral closing wedge osteotomy. A lateral closing wedge osteotomy was done for cubitusvarus of the right elbow of a 17 years old girl following a neglected supracondylar fracture of the right humerus. The carrying angle which was $18 \square$ preoperatively became $12 \square$ postoperatively following which the patient did not have any difficulty in fully flexing the elbow and could swing her upper limb freely while walking. Closing wedge supracondylar osteotomy is an effective treatment for cubitusvarus both functionally and cosmetically
\end{abstract}

\section{KEYWORDS:}

Supracondylar fracture, Cubitusvarus, Lateral closing wedge osteotomy

1. Assistant Professor, Department of Orthopedics \& Trauma Surgery, Universal College of Medical Sciences \& Teaching Hospital, Bhairahawa, Nepal

2. Junior Resident, Department of Orthopedics \& Trauma Surgery, Universal college of medical Sciences, Bhairahawa, Nepal

3. Professor, Department of Orthopedics \& Trauma Surgery, Universal College of Medical Sciences \& Teaching Hospital, Bhairahawa, Nepal

4. Associate Professor, Department of Anaesthesiology, Universal College of Medical Sciences Teaching Hospital, Bhairahawa, Rupandehi, Nepal

\author{
For correspondence: \\ Dr. Prakriti Raj Kandel \\ Assistant Professor, \\ Department of Orthopedics \& Trauma Surgery, \\ Universal College of Medical Sciences \& Teaching \\ Hospital, \\ Bhairahawa, Nepal \\ E-mail:pratul22@gmail.com
}




\section{INTRODUCTION}

Supracondylar fracture of humerus being the most common fracture in children still isn't treated timely or properly leading to various complications, cubitusvarus being the most common complication. $^{1-5}$

Cubitusvarus is the most common delayed complication following supracondylar fracture of humerus in children. The immediate and late causes that results in cubitusvarus deformity are medial angulations, medial rotation, overgrowth of lateral condyle and osteonecrosis or delayed growth of medial condyle. ${ }^{6}$ They may sometimes result in a 'lazy S' deformity in the lateral condylar region along with partial stiffness of the elbow, as a complication of surgical trauma to the peri-articular soft tissue and postoperative immobilisation.

\section{CASE REPORT}

Our patient, a female of 17 years of age, presented to the Out Patient Department with the chief complaint of a crooked right elbow, inability to completely flex the same elbow and discomfort on swinging the right upper limb while walking for 7 years. According to the patient, she sustained injury to her right elbow 7 years back after she fell down a staircase. At that time, she had pain and swelling over the lower region of her right arm. There wasn't any wound or deformity at the time of injury. She was first taken to a homeopathic physician where she was given ayurvedic medicines and pastes were applied on her elbow. As her pain did not subside, swelling increased and blisters also started forming, she was taken to a clinic in Butwal, where she was told to return after her blisters subsided. No x-rays were obtained nor was the elbow joint splinted. By the time her blisters had subsided, her pain too was gone but she was left with a deformity of the elbow. She described the deformity as non-progressive, that is, the deformity hasn't increased over the past 7 years. It is painless and it only restricts extreme flexion of the elbow joint. There is no history of tingling sensation or numbness over the right forearm and hand.

\section{Preoperative examination}

The range of movement of her right elbow was $0-120$ compared to $0-145 \square$ on her left elbow. The humerus-elbowwrist angle was measured on anteroposterior radiographs that accurately reflected the outline of the upper extremities. The radiographs were taken with the patient sitting in a chair, the hand \& forearm were supinated \& elbow fully extended on the $\mathrm{x}$-ray table. The humerus-elbow-wrist angle was measured by drawing two transverse lines (one proximal \& one distal) across the forearm that connected the medial cortex of the ulna $\&$ lateral cortex of the radius. We then drew a line connecting the midpoints of the two cross-humeral lines and another connecting the midpoints of the two lines across the forearm. These lines were extended until they intersected, and the angle of intersection was measured with a goniometer.

\section{Preoperative plan for Osteotomy}

We determined the correction angle by comparing the humerus-elbow-wrist angles of the normal and deformed elbows. Care was taken to ensure that the elbow was fully extended and the forearm was supinated for such radiographs.

\section{Operative procedure}

Osteotomy was performed at the diaphysiometaphyseal junction just above the olecranon fossa. Wedge bone base width was of $3 \mathrm{~cm}$. With fluoroscopic guidance, two Kirschner wires were inserted into the lateral condyle before osteotomy and advanced just distal to the planned distal cut, ready to advance these proximally after the closing wedge osteotomy was made. Closing wedge osteotomy was made laterally, leaving the medial cortex intact which was weakened using drill holes and a rongeur.A forceful valgus stress was applied to complete the osteotomy with the forearm in pronation and the elbow flexed. The osteotomy was then closed and the Kirshcner wires were advanced from the lateral condyle into the medial cortex of the proximal fragment. The wires were left buried under the skin. 2 more Kirschner wires were inserted from the medial condyle to the lateral cortex of the proximal fragment for more stability. After closing the wound, a posterior above elbow slab was applied in $90 \square$ with the forearm in full pronation.

\section{Post-operative management and rehabilitation}

Post-operatively, dressing was done on every third day and during each dressing, passive flexion and extension was done by the surgeon and the limb again kept in slab after dressing. Sutures were removed on the $13^{\text {th }}$ post-operative day. The slab was continued for a total of 6 weeks following which the kwires were removed and the slab discarded. Active elbow flexion and extension exercises were started immediately. The carrying angle which was $18^{\circ}$ preoperatively became $12^{\circ}$ postoperatively. The patient now has no difficulty in full extension and flexion of the elbow. The flexion of her right elbow which was initially $0-120^{\circ}$, improved to $0-140^{\circ}$. She no longer has any discomfort in swinging her upper limb while walking.

\section{DISCUSSION}

Since Siris ${ }^{7}$ first described a lateral closing wedge osteotomy for the correction of cubitusvarus deformity in 1939, various types of osteotomy have been proposed. The three major types are the simple lateral closing wedge, the step-cut lateral closing wedge, and the dome rotational osteotomy. The shortcoming with a simple step-cut osteotomy is that there is limited medial and lateral translation of the distal fragment ${ }^{8}$. The distal fragment can be rotated only in the horizontal plane to correct the deformity. It is similar to the lateral closing wedge osteotomy, except for the stabilization of the osteotomy 
site with a step-cut and fixation with a single screw. Since this requires immobilization in a cast for a long term, it is not preferred in adolescents and adults. A dome osteotomy ${ }^{9,10}$ can reorient the distal fragment in both the coronal and the horizontal plane, avoiding the residual prominence of the medial and lateral condyles that are usually seen after other osteotomies. However, because of contracture of the surrounding soft tissue often makes it difficult to rotate the distal portion in the coronal plane and frequently some prominence of the condyles remains.

\section{CONCLUSION}

Lateral closing wedge osteotomy is easy and safe, but it has several problems. It is hard to achieve a strong internal fixation, so early exercise is difficult. In addition, protrusion of the lateral condyle and a lazy-s deformity of the elbow was observed postoperatively.
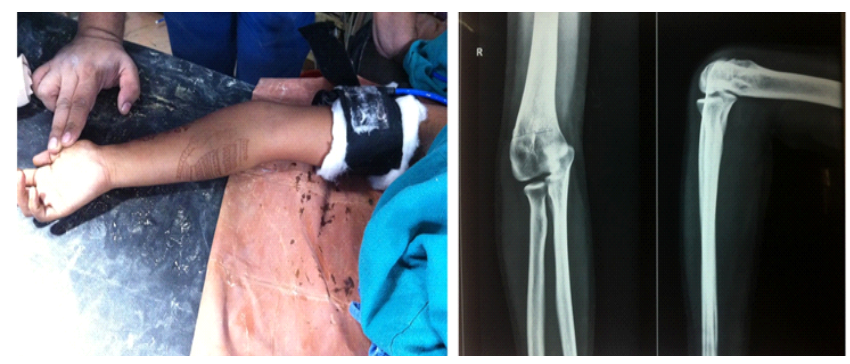

Figure 1: Pre-operative Gun-stock deformity of the right elbow and $\mathrm{x}$-ray of the right elbow in AP and lateral views

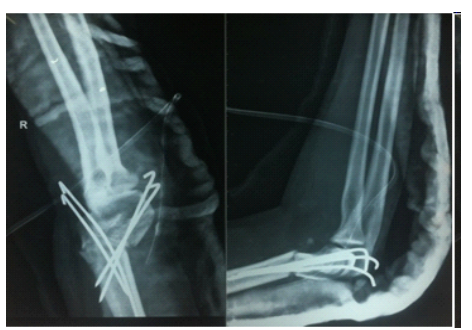

Figure 2: Immediate post-operative $x$-ray of right elbow (AP $\&$ lateral views)
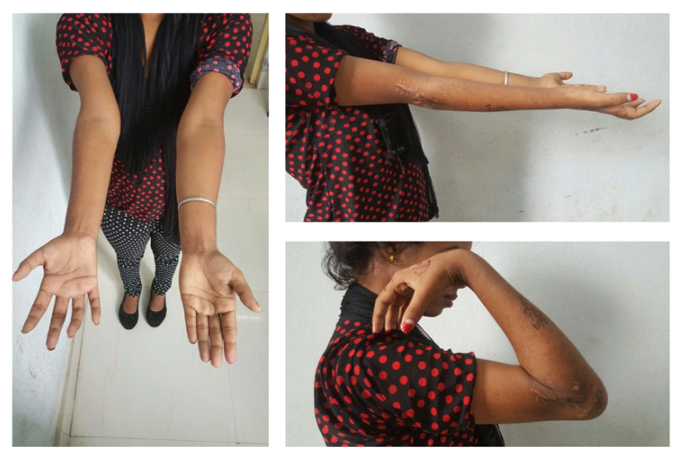

Figure 3: Post-operative functional outcome of the patient at 3 months follow-up

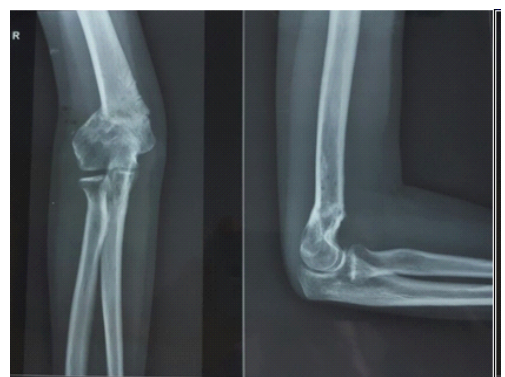

Figure 4: Post-operative x-ray of right elbow in AP and lateral view at 3 months follow-up.

\section{REFERENCES:}

1. Bellemore MC, Barrett IR, Middleton RW, Scougall JS, Whiteway $D W$. Supracondylar osteotomy of the humerus for correction of cubitusvarus. J Bone Joint Surg Br 1984;66:56672.

2. French PR. Varus deformity of the elbow following supracondylar fracture of the humerus in children. Lancet 1959;2:43941.

3. Laupattarakasem $W$, Mahaisavariya B, Kowsuwon $W$, Saengnipanthkul S. Pentalateral osteotomy for cubitusvarus. Clinical experiences of a new technique. J Bone Joint Surg Br 1989;71:66770.

4. Nasser A. Correction of varus deformity following supracondylar fracture of the humerus. J Bone Joint Surg Br 1974;56:5723.

5. Wong HK, Lee EH, Balasubramaniam P. The lateral condylar prominence. A complication of supracondylar osteotomy for cubitusvarus. J Bone Joint Surg Br 1990;72:85961.

6. Yun YH. Modified step-cut osteotomy of distal humerus for the correction of cubitusvarus deformity [in Korean]. J KoreaOrthopAssoc 1998;33:108291.

7. Siris IE. Supracondylar fracture of the humerus: analysis of 330 cases. Surg Gynecol Obstet. 1939;68:201-22.

8. DeRosa GP, Graziano GP. A new osteotomy for cubitus varus. Clin Orthop. 1988;236:160-5.

9. Kanaujia RR, Yoshioka K, Murakami T. A fixation device for corrective osteotomy: brief report. J Bone Joint Surg Br. 1988; 70:223.

10. Wilkins KE, Beaty JH, Chamber HG, Toniolo RM, Sanders JO, Curtis RJ. Fractures and dislocations of the elbow region. In: RockwoodCA Jr, Wilkins KE, Beaty JH, editors. Fractures in children. 4th ed. Philadelphia: Lippincott-Raven; 1996.p 653904. 